\title{
Co-morbidity and drug treatment in Alzheimer's disease. A cross sectional study of participants in the Dementia Study in Northern Norway
}

\author{
Fred Andersen ${ }^{1 *}$, Matti Viitanen ${ }^{2}$, Dag S Halvorsen ${ }^{3}$, Bjørn Straume $^{4}$ and Torgeir A Engstad ${ }^{5+}$
}

\begin{abstract}
Background: Inappropriate medical treatment of co-morbidities in Alzheimer's disease (AD) is an increasing concern in geriatric medicine. The objective of this study was to compare current drug use related to co-morbidity between individuals with a recent diagnosis of $A D$ and a cognitively healthy control group in a population based clinical trial in Northern Norway.

Methods: Setting: Nine rural municipalities with 70000 inhabitants in Northern Norway.

Participants: Participants with and without AD recruited in general practice and by population based screening. 187 participants with a recent diagnosis of AD were recruited among community dwellers. Of 791 respondents without cognitive symptoms, 500 were randomly selected and invited to further clinical and cognitive testing. The final control group consisted of 200 cognitively healthy individuals from the same municipalities. Demographic characteristics, data on medical history and current medication were included, and a physical and cognitive examination was performed. The statistical analyses were carried out by independent sample t-test, chi-square, ANCOVA and logistic regression.
\end{abstract}

Results: A co-morbidity score was significantly higher in AD participants compared to controls. The mean number of drugs was higher for AD participants compared to controls (5.1 \pm 3.6 and $2.9 \pm 2.4$ respectively, $p<0.001$ age and gender adjusted), also when adjusted for co-morbidity. AD participants used significantly more anticholinergic, sedative and antidepressant drugs. For nursing home residents with $A D$ the mean number of drugs was significantly higher compared to AD participants living at home $(6.9 \pm 3.9$ and $4.5 \pm 3.3$, respectively, $p<0.001)$.

Conclusions: AD participants were treated with a significantly higher number of drugs as compared to cognitively healthy controls, even after adjustment for co-morbidity. An inappropriate use of anticholinergic and sedative drugs was identified, especially among nursing home residents with AD. The drug burden and the increased risk of adverse reactions among individuals suffering from AD need more attention from prescribing doctors.

\section{Background}

The proportion of elderly with age-related diseases is rapidly increasing worldwide representing a vulnerable population with respect to medication issues. In particular, this is true for Alzheimer's disease (AD), constituting $65-70 \%$ of all dementia subtypes, inflicting an extensive and serious impact on activities of daily living

\footnotetext{
*Correspondence: frea@online.no

+ Contributed equally

'Department of Community Medicine, University of Tromsø, (Breivika),

Tromsø, (9037), Norway, and Árran Lulesami Centre, (Sentrum), Drag, (8270),

Norway

Full list of author information is available at the end of the article
}

and quality of life for patients and their caregivers [1-5]. The prevalence of AD increases by age [6-8] as does a number of other age related disorders.

Individuals suffering from $\mathrm{AD}$ often have cardiovascular diseases such as coronary heart disease, stroke, diabetes mellitus and hypertension, requiring use of multiple drugs. Schubert et al. reported that patients with dementia attending primary care have on average 2.4 chronic conditions and receive 5.1 medications [9]. Likewise, psychiatric disorders like depression and sleeping disturbances are prevalent. Twenty-five to $35 \%$ of $\mathrm{AD}$ individuals have sleep disturbances being treated with hypnotics [10]. Particularly, anxiolytic-hypnotic

\section{Ciomed Central}


agents, antidepressants and antihistamines that often exhibit central nervous system effects are associated with increased cognitive impairment, sedation and confusion. Consequently, multiple drug prescriptions are leaving elderly vulnerable to adverse reactions [10-12] and harmful interactions between psychotropic drugs and between psychotropic drugs and drugs aimed to treat co-morbidities, often classified as inappropriate drug prescriptions [13].

Despite the heavy drug load elderly are exposed to, few studies have examined overall medication in dementia [12], and even fewer studies have focused on appropriate medical treatment of co-morbidity in $\mathrm{AD}$ patients $[14,15]$.

The main purpose of this paper is to compare drug treatment in relation to co-morbidity, focusing on inappropriate prescriptions between individuals with a recent diagnose of $\mathrm{AD}$ and a randomly selected cognitively healthy control group.

\section{Methods}

\section{Participants}

From January 2006 to March 2008187 participants with a recent diagnosis of a probable AD were included in The Dementia Study in Northern Norway, run in nine rural municipalities with 70000 inhabitants (11807 individuals $>=65$ year). Forty-five $\mathrm{AD}$ participants were nursing home residents. The two different recruitment methods which were used and the baseline characteristics comparing the two samples are described in an earlier paper [16]. AD participants were recruited by general practitioners $(n=87)$ and by a population based screening $(\mathrm{n}=100)$. The latter method also recruited a cognitively healthy control group $(n=200)$ (Figure 1$)$. The present study is a cross sectional comparison between AD participants in a randomised controlled trial and a cognitively healthy control group.

\section{Clinical examination}

All AD participants and the cognitively healthy controls passed the same examinations performed by trained physicians and nurses. Dementia and AD were diagnosed by GPs and geriatric specialists using the ICD-10 [17] criteria and the Statistical Manual of Mental Disorders fourth edition (DSM-IV-TR) [18]. Diagnostic discrepancies were discussed with a geriatric colleague and solved by consensus advised by National Institute of Neurological Disorders and Stroke-Alzheimer Disease and Related Disorders (NINCDS-ADRDA) [19] criteria for probable $\mathrm{AD}$. A third specialist (MV) was consulted if disagreement continued. Blood pressure was measured automatically by DINAMAP ProCare [20]. Three consecutive blood pressures were recorded and the mean of the second and the third measures was used to calculate mean arterial blood pressure (MAP). Body mass index (BMI) was calculated. A 12 channels electrocardiogram (ECG) was registered. Cognition was tested at entry by Mini-Mental-State-Examination (MMSE) [21] and Clock drawing test [22]. Prior to the study onset two test technicians were trained at the Geriatric Department, University Hospital in Northern Norway. To improve intra- and inter-rater reliability they observed and evaluated each other by testing a number of patients with MMSE, Alzheimer's disease Assessment Scale, cognitive (ADAS-Cog) [23] and Neuropsychiatric Inventory (NPI) [24].

\section{Medical history}

The demographic characteristics and self-reported medical history were registered in a questionnaire regarding the most common life style and age related illnesses like cardiovascular diseases (i.e. myocardial infarct, angina pectoris, congestive heart failure, atrial fibrillation), hypertension, stroke, diabetes, chronic pain and neuropsychiatric complains. A co-morbidity score was calculated for each participant by adding the number of age related diseases identified as AD risk factors $[25,26]$ providing a sum score of chronic health conditions [9]. The physicians had access to the medical record of AD participants confirming given information. In addition the caregiver or a next of kin was encouraged to extend the medical history. Computerised ECG assessed by an experienced physician validated a medical history of coronary heart disease.

\section{Drug treatment}

Drugs used at study entry by AD participants and controls were registered and daily medication was checked according to medication charts, information given by caregiver(s) and the medical record. The medication charts were also checked against reported co-morbidities. Drugs were classified and recorded according to the Anatomic Therapeutic Classification system (ATC codes) [27] like anxiolytic-hypnotics (N05B and C) antidepressants (N06A), antipsychotics (N05A), lipid lowering agents (C10A), antihypertensive drugs (C09A, B, C and D, C08C and D, C07A and B, C03A, C, D and E) and a heterogeneous group consisting of drugs with anticholinergic activities. According to the Anticholinergic Drug Scale [28] drugs with anticholinergic activity are grouped into four levels (level 0 - 3) [28-30]. In this study drugs exhibiting a significant or a moderate level of anticholinergic effect (level 2 and 3) were recorded. Inappropriate drugs were classified according to the Screening Tool of Older Persons' Prescription (STOPP) criteria which comprise a list of drugs at risk of interaction and adverse reactions when combined with common illnesses in geriatric practice [13]. 


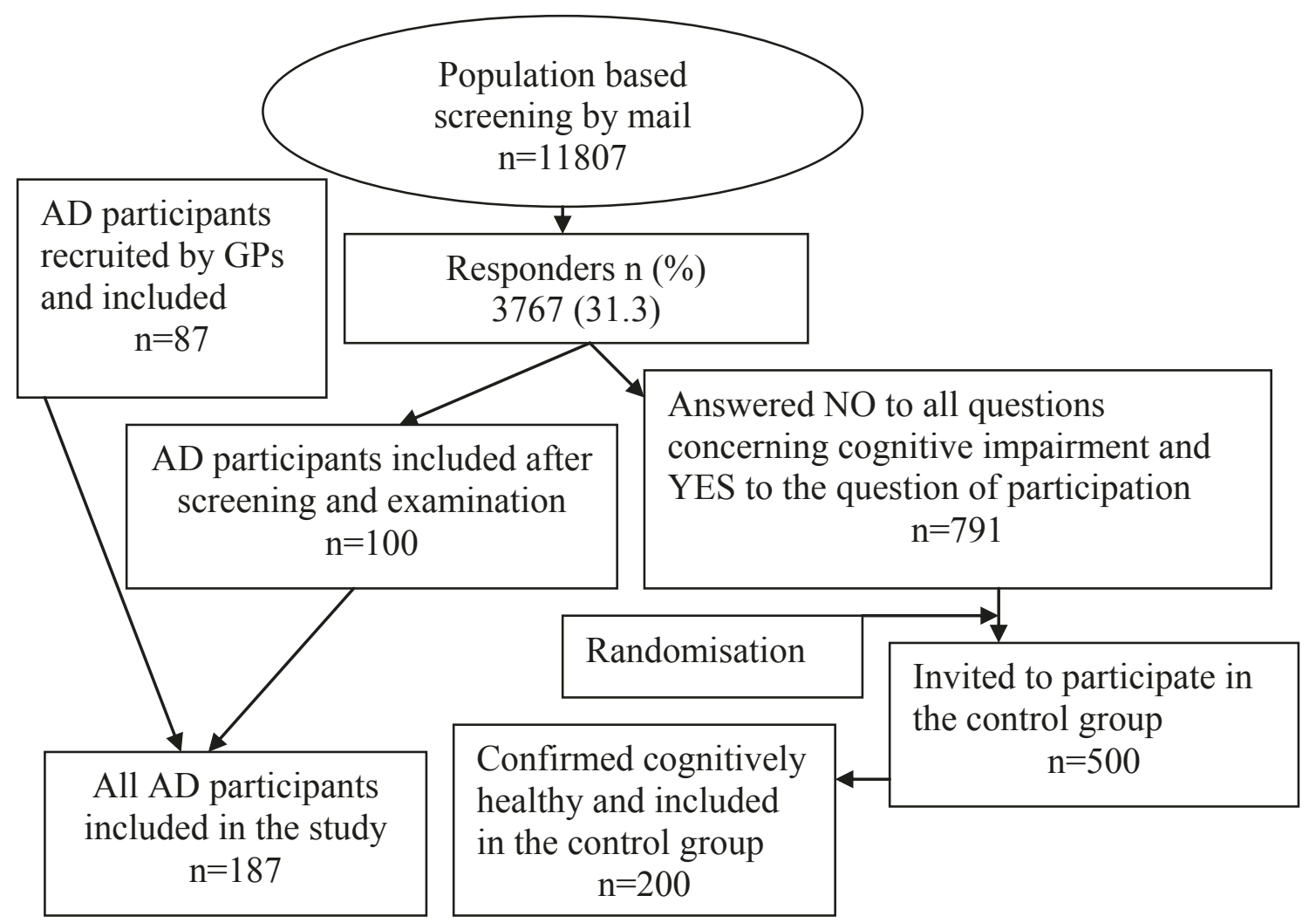

Figure 1 Flowchart revealing recruitment methods and participants.

\section{Approvals}

The Dementia study in Northern Norway complies with the Norwegian Research Legislation and the Helsinki Declaration, and the present manuscript complies with the CONSORT statement. The Regional Committee for Medical Research Ethics in Northern Norway, The Privacy Ombudsman for Research, The Directory of Health and Social Welfare and The Norwegian Medicine Agency including registration in the EudraCT database (no 2004-002613-37) approved the study. Each AD participant gave a written informed consent co-signed by a next of kin or a caregiver whereas participants in the cognitively healthy control group gave a written informed consent on their own. The present manuscript is based on data already collected in The Dementia Study in Northern Norway.

\section{Statistics}

Statistical analyses were carried out using SPSS version 18.0 (SPSS Inc. Chicago, US). Differences in age, gender, heredity, co-morbidity and current drug use between participants with and without AD were analyzed by independent sample t-tests and Chi-Square tests. Adjustment for age, gender and co-morbidity score were done by covariance analyses and logistic regression. A two-sided 5\% significance level was used. The results are presented both unadjusted and age and gender adjusted. The calculation of $95 \%$ confidence interval (CI) refers to age and gender adjusted differences between samples or groups according to the ANCOVA or to logistic regression analyses.

\section{Result}

\section{Baseline characteristics}

AD participants were older $(\mathrm{p}<0.001)$, more often female $(\mathrm{p}<.0 .001)$ and reported dementia among close relatives $(\mathrm{p}<0.001)$ more frequently compared to controls. Mean arterial blood pressure was significantly lower among AD participants compared to controls ( $\mathrm{p}=$ 0.009 age and gender adjusted) (Table 1).

\section{Medical history}

The co-morbidity score was higher in AD participants compared to controls $(2.1 \pm 1.5$ and $1.3 \pm 1.2$ respectively, $\mathrm{p}<0.001)$. AD participants had a higher frequency of cardiovascular diseases (i.e. angina pectoris, myocardial infarct, congestive heart failure and atrial fibrillation), stroke, diabetes mellitus, hypertension, chronic obstructive bronchitis and chronic pain but significantly for chronic obstructive bronchitis only 
Table 1 Baseline characteristics of AD participants compared to controls

\begin{tabular}{|c|c|c|c|}
\hline & $\begin{array}{c}A D \\
n=187\end{array}$ & $\begin{array}{l}\text { Control } \\
n=200\end{array}$ & $p$-value \\
\hline \multicolumn{4}{|l|}{ Age (years \pm SD) } \\
\hline & $80.9 \pm 7.0$ & $72.5 \pm 5.5$ & $<0.001$ \\
\hline \multicolumn{4}{|l|}{ Gender, women } \\
\hline n (\%) & $113(60)$ & $85(43)$ & $<0.001$ \\
\hline \multicolumn{4}{|l|}{ Familiar disposition } \\
\hline $\mathrm{n}(\%)$ & $56(31)$ & $29(15)$ & $<0.001$ \\
\hline \multicolumn{4}{|l|}{ Education $\geq 10$ years } \\
\hline n (\%) & $33(17)$ & $126(63)$ & $0.33^{*}$ \\
\hline \multicolumn{4}{|l|}{ MMSE score \pm SD } \\
\hline & $23.1 \pm 4.5$ & $28.7 \pm 1.6$ & $<0.001^{*}$ \\
\hline \multicolumn{4}{|l|}{$\mathrm{MAP} \pm \mathrm{SD}$} \\
\hline & $100.9 \pm 16.6$ & $107.2 \pm 13.6$ & $0.009^{*}$ \\
\hline \multicolumn{4}{|l|}{$\mathrm{BMI} \pm \mathrm{SD}$} \\
\hline & $25.4 \pm 5.0$ & $26.0 \pm 4.2$ & $0.59^{*}$ \\
\hline
\end{tabular}

*Age and gender adjusted. MAP = Mean arterial blood pressure. $\mathrm{BMI}=$ Body mass index. SD = standard deviation

(adjusted for age and gender) (Table 2). The differences in mean number of co-morbidities were non-significant between $A D$ participants recruited by screening or by GPs $(2.3 \pm 1.5$ and $2.0 \pm 1.6$ respectively, $\mathrm{p}=0.20)$ and between AD participants living at home or in nursing homes $(2.4 \pm 1.6$ and $2.1 \pm 1.5$ respectively, $\mathrm{p}=0.20)$. (Data not shown)

\section{Drug treatment}

The mean number of drugs was significantly higher in AD participants compared to controls $(5.1 \pm 3.6$ and 2.9 \pm 2.4 respectively, age and gender adjusted difference of means $1.48,95 \% \mathrm{CI} 0.78$ to $2.21, \mathrm{p}<0.001)$. This finding remained unchanged when adjusting for co-morbidity score $(\mathrm{p}<0.001)$. Forty-eight percent of AD participants used five or more drugs compared to $23 \%$ in the control group $(95 \% \mathrm{CI}$ for age and gender adjusted differences 0.076 to $0.298, \mathrm{p}=0.001$ ) (Table 3 ). AD participants used a greater number of antihypertensive drugs. Inappropriate drugs such as anticholinergics, antidepressants and anxiolytic/hypnotics were prescribed more frequently to AD participants compared to controls (Table 3).

The total number of prescribed drugs was significantly higher among nursing home residents with AD $(n=45)$ compared to AD participants living at home $(6.9 \pm 3.9$ and $4.5 \pm 3.3$ respectively, age and gender adjusted differences of means $-2.07,95 \% \mathrm{CI}-3.30$ to $-0.83, \mathrm{p}=$ 0.001 ). Nursing home residents with AD used significantly more antidepressants (13 of 45 and 11 of 142 respectively, $\mathrm{p}<0.001$ ) and anxiolytic-hypnotics (18 of 45 and 23 of 141, p < 0.001) compared to AD participants living at home. No significant differences in number of drugs was detected between AD participants when MMSE score was grouped as a dichotomized variable $(=<21$ or $>21)(5.8 \pm 4.2$ versus $4.8 \pm 3.2$ respectively, $\mathrm{p}=0.16$, age and gender adjusted) or between

Table 2 Co-morbidities AD participants compared to controls

\begin{tabular}{|c|c|c|c|c|c|}
\hline & & $\begin{array}{c}\text { AD participants } \\
n=187\end{array}$ & Controls $n=200$ & $\begin{array}{l}\text { Unadjusted } \\
\text { p-value }\end{array}$ & Adjusted p-value* \\
\hline \multicolumn{6}{|c|}{ Co-morbidity score } \\
\hline & & $2.1 \pm 1.5$ & $1.3 \pm 1.2$ & $<0.001$ & $<0.001$ \\
\hline \multicolumn{6}{|c|}{ Cardiovascular diseases** } \\
\hline & n (\%) & $139(74)$ & $114(57)$ & $<0.001$ & 0.14 \\
\hline \multicolumn{6}{|c|}{ Angina pectoris } \\
\hline & n (\%) & $48(26)$ & $18(9)$ & $<0.001$ & 0.37 \\
\hline \multicolumn{6}{|c|}{ Myocardial infarct } \\
\hline & n (\%) & $27(14)$ & $24(12)$ & 0.52 & 0.26 \\
\hline \multicolumn{6}{|c|}{ Atrial fibrillation } \\
\hline & n (\%) & $34(18)$ & $18(9)$ & 0.008 & 0.40 \\
\hline \multicolumn{6}{|l|}{ Stroke } \\
\hline & n (\%) & $33(18)$ & $11(6)$ & $<0.001$ & 0.82 \\
\hline \multicolumn{6}{|l|}{ Hypertension } \\
\hline & n (\%) & $102(55)$ & $82(41)$ & 0.008 & 0.14 \\
\hline \multicolumn{6}{|c|}{ Diabetes mellitus } \\
\hline & n (\%) & $21(11)$ & $17(9)$ & 0.37 & 0.15 \\
\hline \multicolumn{6}{|c|}{ Chronic obstructive bronchitis } \\
\hline & n (\%) & $19(10)$ & $10(5)$ & 0.054 & 0.003 \\
\hline \multicolumn{6}{|l|}{ Chronic pain } \\
\hline & n (\%) & $47(25)$ & $41(21)$ & 0.28 & 0.17 \\
\hline
\end{tabular}

* Adjusted for age and gender. ** Participants suffering from one or more of congestive heart failure, angina pectoris, myocardial infarct, angina pectoris or atrial fibrillation. 
Table 3 Current drug use in AD participants compared to controls

\begin{tabular}{|c|c|c|c|c|c|c|}
\hline & & $\begin{array}{c}\text { AD } \\
n=187\end{array}$ & $\begin{array}{l}\text { Control } \\
n=200\end{array}$ & Difference* & $95 \% \mathrm{Cl}^{*}$ & p-value* \\
\hline \multicolumn{7}{|c|}{ Mean number of drugs $\pm S D$} \\
\hline & & $5.1 \pm 3.6$ & $2.9 \pm 2.4$ & 1.48 & 0.78 to 2.21 & $<0.001$ \\
\hline \multicolumn{7}{|c|}{ Mean number of antihypertensive drugs $\pm S D$} \\
\hline & & $1.4 \pm 1.3$ & $0.8 \pm 0.9$ & 0.28 & 0.012 to 0.538 & 0.040 \\
\hline \multicolumn{7}{|c|}{ Participants using five drugs or more } \\
\hline & $n(\%)$ & $90(48)$ & $46(23)$ & 0.19 & 0.076 to 0.289 & 0.001 \\
\hline \multicolumn{7}{|l|}{ antihypertensive drugs } \\
\hline & $n(\%)$ & $128(68)$ & $101(50)$ & 0.039 & -0.074 to 0.153 & 0.50 \\
\hline \multicolumn{7}{|l|}{ anticholinergic drugs } \\
\hline & $n(\%)$ & $43(23)$ & $12(6)$ & 0.161 & 0.080 to 0.243 & $<0.001$ \\
\hline \multicolumn{7}{|l|}{ antidepressants } \\
\hline & $n(\%)$ & 24(13) & $4(2)$ & 0.091 & 0.030 to 0.151 & 0.004 \\
\hline \multicolumn{7}{|c|}{ anxiolytic-hypnotic drugs } \\
\hline & $n(\%)$ & $42(22)$ & $15(8)$ & 0.090 & 0.008 to 0.172 & 0.032 \\
\hline \multicolumn{7}{|l|}{ inappropriate drugs ${ }^{* *}$} \\
\hline & $n(\%)$ & $69(37)$ & $22(11)$ & 0.193 & 0.097 to 0.288 & $<0.001$ \\
\hline \multicolumn{7}{|l|}{ lipid lowering agents } \\
\hline & $\mathrm{n}(\%)$ & $53(28)$ & $69(35)$ & 0.000 & -0.111 to 0.112 & 0.99 \\
\hline
\end{tabular}

$\mathrm{SD}=$ Standard deviation. $\mathrm{Cl}=$ Confidence interval for age and gender adjusted differences. * Age and gender adjusted. Percentage differences in Cls are expressed in fractions. ${ }^{* *}$ According to STOPP criteria for inappropriate drug treatment

AD participants recruited by screening or by GPs $(5.0 \pm$ 3.5 versus $5.2 \pm 3.7$ respectively, $\mathrm{p}=0.56$ age and gender adjusted) (Data not shown).

\section{Discussion \\ Medical history}

The co-morbidity score was significantly higher in AD participants compared to controls but turned out nonsignificant for nine of ten recorded co-morbidities when adjusting for age and gender. This is in line with other studies $[9,31,32]$ whereas one study using a historical cohort of community dwellers with and without $\mathrm{AD}$ reported a significant higher prevalence for 12 of 14 health conditions among AD individuals [33].

In our study, $\mathrm{AD}$ participants reported higher lifetime occurrence of hypertension and were more often treated with a greater number of antihypertensive drugs. Previous observations have shown that $A D$ is associated with elevated systolic blood pressure in midlife followed by a greater decrease with aging compared to cognitively healthy individuals $[31,34]$. Midlife hypertension may generate arteriosclerosis, cerebral small-vessel disease and disturbed cerebral autoregulation in resistant arteries [35-37], leaving elderly AD individuals prone to cerebral hypoperfusion and cognitive worsening due to extensive antihypertensive treatment $[38,39]$.

\section{Drug treatment}

In the present study AD participants consumed a significant higher number of drugs compared to controls, similar to the results reported by Schubert et al [9]. Adjusting for co-morbidity score did not change the results. Any prescription has a potential risk of adverse reactions and the risk increases with the number of drugs, from a $10 \%$ with one drug to $75 \%$ with five or more drugs [40]. In our study $48 \%$ of the AD participants used five or more drugs compared to $23 \%$ of the controls. The nursing home AD residents consumed a mean of $6.9 \pm 3.9$ different drugs a day, quite similarly to what Holmes et al reported [41].

Inappropriate medication is based on the STOPP criteria [13], and in our study $37 \%$ of the AD participants used one or more drugs considered inappropriate compared to $11 \%$ in the control group ( $\mathrm{p}<0.001)$ (Table 3). In a recent paper Barnett et al concluded that the high prevalence of inappropriate drugs in older people continues to occur despite the recognition and concerns of iatrogenic harms [42].

In the present study $\mathrm{AD}$ participants were significantly more often treated with drugs with anticholinergic side effects compared to controls ( $\mathrm{p}<0.001)$. Drugs with anticholinergic properties are considered inappropriate in elderly patients as a consequence of adverse reactions including constipation, dry mouth, blurred vision and dizziness which may contribute to falls and delirium [43]. Increased levels of anticholinergic activity are associated with increased cognitive decline assessed by MMSE and even dementia [11,44-46]. Interruption of the anticholinergic medication may represent a therapeutic option to improve cognitive performance [47], 
especially where anticholinergic drugs are give simultaneously with cholinesterase inhibitors.

In our study, anxiolytic-hypnotics and antidepressants were used more frequently in the AD group compared to the control group $(\mathrm{p}=0.032)$. Among nursing home AD residents 18 of 45 (40\%) used anxiolytic-hypnotics. In another study $20 \%$ of $\mathrm{AD}$ individuals in general practice were prescribed at least one psychotropic drug. Anxiolytic-hypnotic drugs are known to influence alertness, power of reaction, risk of falls and functional and cognitive impairment [48].

\section{Strengths and weaknesses}

This study has a population-based design and is accomplished on a community level providing a homogenous sample with minimal environmental influence. The participants in this study were examined according to standardized procedures and diagnoses were based on accepted validated criteria and were confirmed by an expert panel. A self-report of the medical history by AD participants could be inaccurate and at risk of recall bias, but the method is in accordance with several geriatric studies based on self-reported chronic medical conditions [40].

A weakness of the study is that defined daily doses of medication and the length of treatment have not been recorded. The differences in mean age and gender distribution between the AD group and the control group are significant, but adjustment for age and gender was performed in the statistical analyses. However, age and gender adjustment is questionable when it comes to some of the variables like familiar disposition and prevalence of hypertension.

\section{Conclusion}

In the present study AD participants used more drugs than cognitively healthy controls despite similar frequency of co-morbidity. The AD participants had nearly a two-fold use of drugs and inappropriate use of anticholinergic, anxiolytic-hypnotic and antidepressants were detected. The drug burden and the increased risk of adverse reactions among individuals suffering from $\mathrm{AD}$ need more attention from prescribing doctors.

\section{List of abbreviations}

AD: Alzheimer's disease; ADAS-Cog: Alzheimer's disease Assessment Scale, cognitive (Scale 0-70, increasing disability with increasing score); ATC: Anatomic Therapeutic Classification system; BMI: Body Mass Index; Cl: Confidence interval; DSM-IV-TR: Statistical Manual of Mental Disorders fourth edition; ECG: Electrocardiogram; GP: General Practitioner; ICD-10: International classification of diseases $10^{\text {th }}$ Revision; MAP: Mean arterial blood pressure; MMSE: Mini-Mental State Examination (Scale 0-30, better function with increasing score); NPI: NeuroPsychiatric Inventory (Scale 0-144, increasing disability by increasing number); NINCDS-ADRDA: National Institute of Neurological Disorders and Stroke-Alzheimer Disease's and Related Disorders; SD: Standard deviation; STOPP: Screening Tool for Older Persons' Prescription.

\section{Acknowledgements}

We want to express our gratitude to the patients, nurses and general practitioners who participated and contributed to this study. We are grateful to the staff at the study centre in Steigen, Kristin Tverback, Merete Hjertø and Herdis Svendsen for daily administration, testing and monitoring. We want to thank Inger Sperstad and the Clinical Research Centre, University of Tromsø for randomizing patients and data support, Per Baadnes at The

Department of Community Medicine, University of Tromsø, for support with the screening procedure, and the staff at the pharmacy in Nordland Central Hospital for medical distribution. Finally we would like to thank our sponsors (See Funding) for necessary economic support and at last, but not least, the Scientific Advisory Board for their important methodological and clinical guidance. Permission to the acknowledgement is obtained from all the persons named above

Funding

The Northern Norway Regional Health Authority, The National Centre of Rural Health at The University of Tromsø, Health and Rehabilitation, The Directory of Health and Social Welfare in Norway, The County Officer of Nordland and The Municipality of Steigen constituted the funding group.

\section{Author details}

${ }^{1}$ Department of Community Medicine, University of Troms $\varnothing$, (Breivika), Tromsø, (9037), Norway, and Árran Lulesami Centre, (Sentrum), Drag, (8270), Norway. ${ }^{2}$ Department of Geriatrics, Karolinska Institutet, (Huddinge), Stockholm, (141 86) Sweden, and University of Turku, (Sirkkalankatu), Turku, (20520), Finland. ${ }^{3}$ Department of Medicine, University hospital, (Breivika), Tromsø, (9038), Norway. ${ }^{4}$ Department of Community Medicine, University of Troms $\varnothing$, (Breivika), Tromsø, (9037), Norway. ${ }^{5}$ Department of Geriatrics, University Hospital, (Breivika), Tromsø, (9038), Norway.

\section{Authors' contributions}

FA has initiated, coordinated and conducted this study in close co-operation with the scientific advisory board at The University of Tromsø. He has examined and diagnosed patients recruited both in general practice and by postal cognitive screening. He is also responsible for analyzing baseline data, the main results of the study and the cross sectional analyses referred in the present paper. MV is a member of the scientific advisory board and has participated in planning of the present study and in revising this manuscript. DSH has contributed significantly in drafting and writing of this paper. BS participated in the planning of the study, supervising implementation and analysis and has revised the manuscript. He is a member of the scientific advisory board. TE has been the main supervisor and member of the scientific advisory board, participating in all stages of this study; - planning, lecturing, collecting data, discussing results and writing. All authors have full access to all the data (including statistical reports and tables) and have approved the final version of the paper.

\section{Competing interests}

The authors declare that they have no competing interests.

Received: 10 May 2011 Accepted: 4 October 2011

Published: 4 October 2011

\section{References}

1. Aarsland D, Rongve A, Nore SP, Skogseth S, Skulstad S, Ehrt U, Hoprekstad D, Ballard C: Frequency and case identification of dementia with Lewy bodies using the revised consensus criteria. Dement Geriatr Cogn Disord 2008, 26:445-452.

2. Bermejo-Pareja F, ito-Leon J, Vega S, Medrano MJ, Roman GC: Incidence and subtypes of dementia in three elderly populations of central Spain. J Neurol Sci 2008, 264:63-72.

3. Ferrara M, Langiano E, Di BT, De VE, Di CL, Bauco C: Prevalence of stress, anxiety and depression in with Alzheimer caregivers. Health Qual Life Outcomes 2008, 6:93.

4. Kivipelto M, Laakso MP, Tuomilehto J, Nissinen A, Soininen H: Hypertension and hypercholesterolaemia as risk factors for Alzheimer's disease: potential for pharmacological intervention. CNS Drugs 2002, 16:435-444.

5. Plassman BL, Langa KM, Fisher GG, Heeringa SG, Weir DR, Ofstedal MB, Burke JR, Hurd MD, Potter GG, Rodgers WL, Steffens DC, Willis RJ, Wallace RB: Prevalence of dementia in the United States: the aging, demographics, and memory study. Neuroepidemiology 2007, 29:125-132. 
6. Trojanowski JQ, Arnold SE, Karlawish JH, Burden K, Cary M, Davatzikos C, Detre J, Gaulton G, Grossman M, Hurtig H, Jedrziewski K, McCluskey L, Naylor M, Polsky D, Schellenberg GD, Siderowf A, Shaw LM, Van DV Wang LS, Werner R, Xie SX, Lee VM: Design of comprehensive Alzheimer's disease centers to address unmet national needs. Alzheimers Dement 2010, 6:150-155.

7. Brookmeyer R, Gray S, Kawas C: Projections of Alzheimer's disease in the United States and the public health impact of delaying disease onset. Am J Public Health 1998, 88:1337-1342.

8. Wimo A, Jonsson L, Gustavsson A, McDaid D, Ersek K, Georges J, Gulacsi L, Karpati K, Kenigsberg P, Valtonen $\mathrm{H}$ : The economic impact of dementia in Europe in 2008-cost estimates from the Eurocode project. Int J Geriatr Psychiatry 2010, 28.

9. Schubert CC, Boustani M, Callahan CM, Perkins AJ, Carney CP, Fox C, Unverzaget $F$, Hendrie $\mathrm{HC}$ : Comorbidity profile of dementia patients in primary care: are they sicker? J Am Geriatr Soc 2006, 54:104-109.

10. Deschenes $\mathrm{CL}$, McCurry SM: Current treatments for sleep disturbances in individuals with dementia. Curr Psychiatry Rep 2009, 11:20-26.

11. Jessen F, Kaduszkiewicz H, Daerr M, Bickel H, Pentzek M, Riedel-Heller S, Wagner M, van den Bussche $\mathrm{H}$, Broich $\mathrm{K}$, Maier W: Anticholinergic drug use and risk for dementia: target for dementia prevention. Eur Arch Psychiatry Clin Neurosci 2010, 260:111-115.

12. Tjia J, Rothman MR, Kiely DK, Shaffer ML, Holmes HM, Sachs GA, Mitchell SL: Daily medication use in nursing home residents with advanced dementia. J Am Geriatr Soc 2010, 58:880-888.

13. Levy HB, Marcus EL, Christen C: Beyond the beers criteria: A comparative overview of explicit criteria. Ann Pharmacother 2010, 44:1968-1975.

14. Brauner DJ, Muir JC, Sachs GA: Treating nondementia illnesses in patients with dementia. JAMA 2000, 283:3230-3235.

15. Stefanacci RG, Cavallaro E, Beers MH, Fick DM: Developing explicit positive beers criteria for preferred central nervous system medications in older adults. Consult Pharm 2009, 24:601-610.

16. Andersen F, Engstad T, Straume B, Viitanen M, Halvorsen DS, Hykkerud S, Sjobrend K: Recruitment methods in Alzheimer's disease research: general practice versus population based screening by mail. BMC Med Res Methodol 2010, 10:35.

17. Bebbington P: Welcome to ICD-10. Soc Psychiatry Psychiatr Epidemiol 1992, 6:255-257.

18. Naik M, Nygaard HA: Diagnosing dementia - ICD-10 not so bad after all: a comparison between dementia criteria according to DSM-IV and ICD10. Int J Geriatr Psychiatry 2008, 3:279-282.

19. Dubois B, Feldman HH, Jacova C, Dekosky ST, Barberger-Gateau P, Cummings J, Delacourte A, Galasko D, Gauthier S, Jicha G, Meguro K, O'Brien J, Pasquier F, Robert P, Rossor M, Salloway S, Stern Y, Visser PJ, Scheltens P: Research criteria for the diagnosis of Alzheimer's disease: revising the NINCDS-ADRDA criteria. Lancet Neurol 2007, 6:734-746.

20. Reinders A, Reggiori F, Shennan AH: Validation of the DINAMAP ProCare blood pressure device according to the international protocol in an adult population. Blood Press Monit 2006, 11:293-296.

21. Folstein MF, Folstein SE, McHugh PR: "Mini-mental state". A practical method for grading the cognitive state of patients for the clinician. $J$ Psychiatr Res 1975, 12:189-198.

22. Sunderland T, Hill JL, Mellow AM, Lawlor BA, Gundersheimer J, Newhouse PA, Grafman JH: Clock drawing in Alzheimer's disease. A novel measure of dementia severity. J Am Geriatr Soc 1989, 37:725-729.

23. Burch EA, Andrews SR: Comparison of two cognitive rating scales in medically ill patients. Int J Psychiatry Med 1987, 2:193-200.

24. Cummings JL, Mega M, Gray K, Rosenberg-Thompson S, Carusi DA, Gornbein J: The Neuropsychiatric Inventory: comprehensive assessment of psychopathology in dementia. Neurology 1994, 12:2308-2314.

25. Wang S, Jacobs D, Andrews H, Tsai WY, Luo X, Bergmann C, Sano M: Cardiovascular risk and memory in non- demented elderly women. Neurobiol Aging 2010, 31:1250-1253.

26. McCarron M, Gill M, McCallion P, Begley C: Health co-morbidities in ageing persons with Down syndrome and Alzheimer's dementia. Intellect Disabil Res 2005, 49:560-566.

27. Skrbo A, Zulic I, Hadzic S, Gaon ID: [Anatomic-therapeutic-chemical classification of drugs]. Med Arh 1999, 53:57-60.

28. Carnahan RM, Lund BC, Perry PJ, Polloc BG, Culp KR: The Anticholinergic Drug Scale as a measure of drug-related anticholinergic burden: associations with serum anticholinergic activity. J Clin Pharmacol 2006 46:1481-1486.

29. National Prescribing Service Limited A. NPS News 59: Drugs used in dementia in the elderly. 2008

30. Rudolph JL, Salow MJ, Angelini MC, McGlinchey RE: The anticholinergic risk scale and anticholinergic adverse effects in older persons. Arch Intern Med 2008, 168:508-513.

31. Guo Z, Viitanen M, Fratiglioni L, Winblad B: Low blood pressure and dementia in elderly people: the Kungsholmen project. BMJ 1996, 312:805-808

32. Zekry D, Herrmann FR, Grandjean R, Meynet MP, Michel JP, Krause KH: Demented versus non-demented very old inpatients: the same comorbidities but poorer functional and nutritional status. Age Ageing 2008, 37:83-89.

33. Malone DC, McLaughlin TP, Wahl PM, Leibman C, Arrighi HM, Cziraky MJ, Mucha LM: Burden of Alzheimer's disease and association with negative health outcomes. Am J Manag Care 2009, 15:481-488.

34. Stewart R, Xue QL, Masaki K, Petrovitch H, Ross GW, White LR, Launer LJ: Change in blood pressure and incident dementia: a 32-year prospective study. Hypertension 2009, 54:233-240.

35. Dhikav V, Anand K: Potential predictors of hippocampal atrophy in Alzheimer's disease. Drugs Aging 2011, 28:1-11.

36. Yip AG, McKee AC, Green RC, Wells J, Young H, Cupples LA, Farrer LA: APOE, vascular pathology, and the AD brain. Neurology 2005, 65:259-265.

37. van Beek $A H$, Claassen JA, Rikkert MG, Jansen RW: Cerebral autoregulation: an overview of current concepts and methodology with special focus on the elderly. J Cereb Blood Flow Metab 2008, 28:1071-1085.

38. Moretti R, Torre P, Antonello RM, Manganaro D, Vilotti C, Pizzolato G: Risk factors for vascular dementia: hypotension as a key point. Vasc Health Risk Manag 2008, 4:395-402.

39. Qiu C, von SE, Fastbom J, Winblad B, Fratiglioni L: Low blood pressure and risk of dementia in the Kungsholmen project: a 6-year follow-up study. Arch Neurol 2003, 60:223-228.

40. Caughey GE, Vitry Al, Gilbert AL, Roughead EE: Prevalence of comorbidity of chronic diseases in Australia. BMC Public Health 2008, 8:221.

41. Holmes HM, Sachs GA, Shega JW, Hougham GW, Cox HD, Dale W: Integrating palliative medicine into the care of persons with advanced dementia: identifying appropriate medication use. J Am Geriatr Soc 2008, 56:1306-1311.

42. Barnett K, McCowan C, Evans JM, Gillespie ND, Davey PG, Fahey T: Prevalence and outcomes of use of potentially inappropriate medicines in older people: cohort study stratified by residence in nursing home or in the community. Qual Saf Health Care 2011, 20:275-281.

43. Uusvaara J, Pitkala KH, Kautiainen H, Tilvis RS, Strandberg TE: Association of anticholinergic drugs with hospitalization and mortality among older cardiovascular patients: A prospective study. Drugs Aging 2011, 28:131-138.

44. Giron MS, Wang HX, Bernsten C, Thorslund M, Winblad B, Fastbom J: The appropriateness of drug use in an older nondemented and demented population. J Am Geriatr Soc 2001, 49:277-283.

45. Carter MD, Simms GA, Weaver DF: The development of new therapeutics for Alzheimer's disease. Clin Pharmacol Ther 2010, 88:475-486.

46. Konishi K, Hori K, Uchida H, Watanabe K, Tominaga I, Kimura M, Shibasaki T, Kataoka A, Hachisu M: Adverse effects of anticholinergic activity on cognitive functions in Alzheimer's disease. Psychogeriatrics 2010, 10:34-38.

47. Campbell N, Boustani M, Limbil T, Ott C, Fox C, Maidment I, Schubert CC, Munger S, Fick D, Miller D, Gulati R: The cognitive impact of anticholinergics: a clinical review. Clin Interv Aging 2009, 4:225-233.

48. Gnjidic D, Le Couteur DG, Abernethy DR, Hilmer SN: Drug Burden Index and Beers Criteria: Impact on Functional Outcomes in Older People Living in Self-Care Retirement Villages. J Clin Pharmacol 2011.

\section{Pre-publication history}

The pre-publication history for this paper can be accessed here: http://www.biomedcentral.com/1471-2318/11/58/prepub

doi:10.1186/1471-2318-11-58

Cite this article as: Andersen et al: Co-morbidity and drug treatment in Alzheimer's disease. A cross sectional study of participants in the Dementia Study in Northern Norway. BMC Geriatrics 2011 11:58. 